\begin{tabular}{|c|c|c|}
\hline $\begin{array}{c}\text { PORT SAID ENGINEERING RESEARCH JOURNAL } \\
\text { Faculty of Engineering - Port Said University } \\
\text { (Production Engineering \& Mechanical Design) }\end{array}$ \\
$\begin{array}{c}\text { No.114-127 } \\
\text { Volume 25 }\end{array}$
\end{tabular}

\title{
Design and Simulation of Mobile CNC Machine; Based Tripod Stewart Platform
}

\author{
Mohamed A.O. Elamirali ${ }^{1}$, Elmoushi Elsayed ${ }^{2}$, Sabreen A. Abdelwahab ${ }^{3}$
}

Received: 5 October 2020; Accepted: 4 January 2021

\begin{abstract}
This paper presents the design model for inverse kinematics Stewart tricept platform as a parallel structure robot which has three fixed prismatic actuators. The portable robot showed fast, consistent and solid structure which recommended to portable Computer Numerically Controlled (CNC) machine that can easily be moved to large parts and perform various operations. The mechanism has 3 degrees of freedom and the 3D model has been built in Solidworks both for design and performance simulation purposes. An exact, analytical geometry method for determining the inverse kinematics solution of a parallel kinematic mobile structure is developed. Machine control elements performance was checked using Simulink and MATLAB software. The proposed parallel manipulator shows better orientation capability and is very meaningful to the development of the multi axes hybrid machine tools.
\end{abstract}

Keywords: Stewart platform; Cost effective design; Portable CNC machines; Robot forward and inverse kinematics.

\section{INTRODUCTION}

It is obvious that machining large components as aerospace and shipping industry, power plants...etc. need to build larger long travels machine. Large rotation and slide movements would be too heavy to be moved and machined precisely. Constructing large machines leads to problems such as lower static and dynamic rigidity, static deflection, high cost of structure-transport-energy, and less accuracy. Manufacturing issues like handling, and machining large parts possess a great impact in time than in size. So, these topics need new research solutions. The evolution from specific task to multi-task machines is increasing, this drives movable machines [1] towards robotics [2], i.e., intelligent machines.

\subsection{Paper structure}

This paper is divided into eight sections, the first is the introduction section, and the second is the literature review section. The third section presents the proposed mechanical design of portable CNC machine and working principal, while the fourth section illustrates the mechanism design in Solidworks. The fifth section.

\footnotetext{
${ }^{I}$ Researcher, Department of Production Technology, Helwan University, Saray El-Quba, 11281, Cairo, Egypt, email: Mohamed.antar.omran@gmail.com.

${ }^{2}$ Assistant professor, Department of Production Technology, Helwan University, Saray El-Quba, 11281, Cairo, Egypt, email: e_elmoushi@yahoo.com

${ }^{3}$ Assistant professor, Department of Production Technology, Helwan University, Saray El-Quba, 11281, Cairo, Egypt, email: engsabreenabdallah@gmail.com
}

DOI: $10.21608 /$ pserj.2021.43738.1063 introduces a solution to the reverse kinematics problem of the mechanism, where section six shows the Simulink model development and dynamics simulation. Section seven displays the mechanism prototype and control circuit, and section eight draws the conclusions, which is followed by the references.

\section{LITERATURE REVIEW}

\subsection{Design concept}

In the past two decades, Parallel Kinematic Machines, Stewart platforms have attracted increasing attention. Each actuated leg has to carry only part of the payload: this is quite energy efficient and allows supporting heavy loads. The parallel structure can reach highly dynamic motions that the end-effector moves. A major problem in practice is the need for spherical joints with a very large angular range and sufficient stiffness at the same time.

In reality, Parallel Kinematic Machines (PKM) lose stiffness at support and link joints which leads to lower dynamics than expected. As motion in three axes is a big challenge. A study of the potentials of PKM compared to classical serial Kinematic Machines (KM) centers was provided by Tlusty [3]. Weck [4] discussed an expanded review of few successful industrial applications of PKM. Combined KM have been used to get good workspace and dynamic behavior. In manufacturing market, a successful solution is the Tricept [5], (Figure 1). It has many machine tools, which combine three parallel axes and two serial rotary axes developing a 5-axes machine. Compared with serial or parallel KM, hybrid combined machine have the advantages of high stiffness, high speed, large workspace, and heterogeneous surface processing ability. Zhang [6] presents a novel parallel machine with one translational 
and two rotational (1T2R) DOFs that form a DOFs hybrid kinematic machine tool for large complex structural in aerospace field (Figure 2). The Ecospeed and Ecoliner Series Machines [7], [8], [9], equipped with the Sprint head is another solution (Figure 3). It has good dynamics, no singularities and low weight. The same result was introduced by Li et al. [10], [11] (Figure 4), but with a variable length arm.

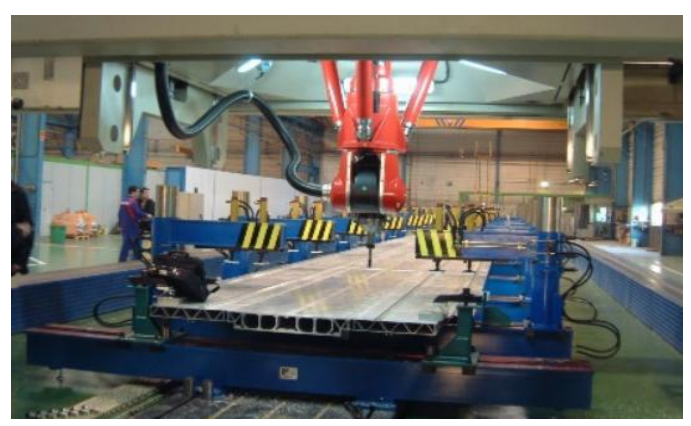

Figure 1: Tricept machine [5]

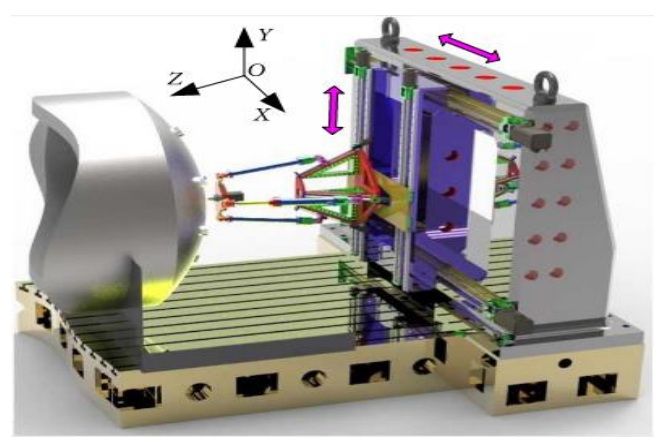

Figure 2: A hybrid kinematic machine with 5 DOFs [6]

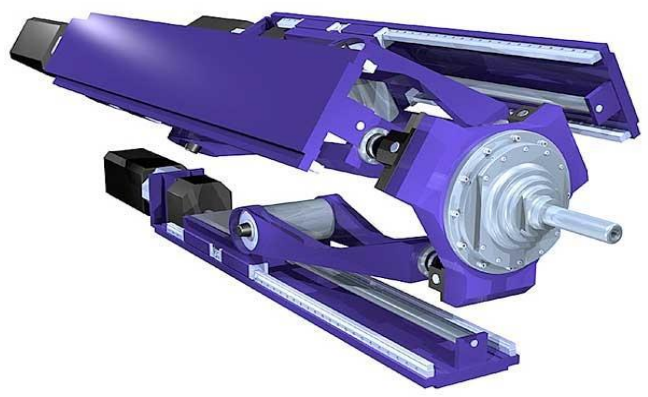

Figure 3. Head Sprint Z3 [9]

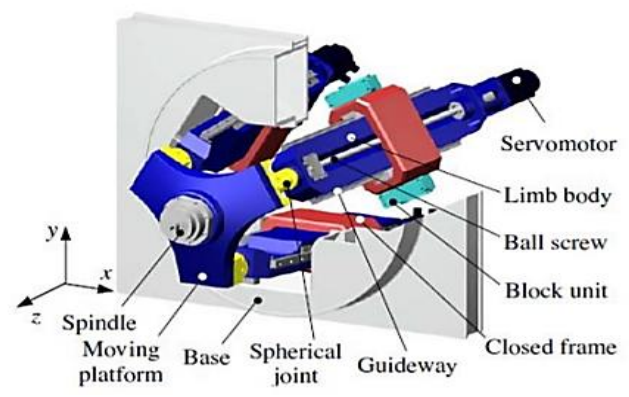

Figure 4. Head by Li et al. [9]

\subsection{Portable machines}

Portable machines enabled the placement of the machinery on/at the work piece, instead of placing the work piece inside a machine, and the production systems transform to the site of operation, that leads to high energy reserves [12] and [13]. Improving dynamic stiffness of structural components leads to improved productivity and dynamics [14]. Reduction in production system size showed smaller components due to smaller loads and no supporting consumers, saving the cost of support systems [15], [16]. Besides, generating energy savings by preventing system oversize [17].

Portable machines can match production process requests with its capabilities [18], [19]. Portable machine mutability enables modifications for long term on manufacturing systems [20], [21] by using modular replacement of sophisticated components [22]. Complex geometric features are machined faster [23].

\subsection{Problem statement}

A 3 DOFs mobile robotic machine tool based on parallel kinematics- Stewart platforms will be designed, to locate all three motions at the spindle head while the part to be machined/repaired in fixed position. The pre discussed drawbacks of large machines would be solved with parallel kinematics mobile machine as it owes lower movable mass, leads to excellent dynamic characteristics in the drives. This work presents a 3D mechanical design of a movable CNC machine using Solidworks. Finite Element Analysis (FEA) have been applied to the CNC machine frame to test its resistance to external loads and choose the suitable material for building up its mechanical design that suits the required application. The reverse kinematic problem of the mechanism will be discussed, the mechanism model development and dynamics simulation will be performed by Simulink. The mobile machine is required to move rapidly and consistently to part location and machine/repair on the site of operation.

\section{MODEL DESIGN OF THE PORTABLE CNC MACHINE AND THE WORKING PRINCIPAL}

A tripod mechanism is proposed based on the PrismaticUniversal-Universal Parallel Kinematic Machine (PUUPKM) [24-27]. The proposed mechanism consists of a base frame; this frame contains a fixed bottom base and a fixed top base which are connected together through six vertical parallel guide ways, these parallel guide ways are distributed where each two are positioned at 120 o with respect to the base frame. Further, the mechanism has three compound screw threads which are powered by three stepper motors via a coupling, each screw thread has a moving nut, the nut is connected to the screw via a Prismatic joint (P), and is connected to two motion arms via a Universal joint (U). The two motion arms are connected from the other side to a movable platform via 
another $U$ joint. Hence, this movable platform can have different motion paths in $\mathrm{X}, \mathrm{Y}$, and $\mathrm{Z}$ directions.

The purpose of the mechanism is to move the movable platform in the three axes of motion (X, Y, and Z). Through controlling the operation of the stepper motors in terms of rotational speed and direction of rotation, the motion is transmitted from the motor to the screw thread via a coupling, the screw thread converts the motion from rotational to linear motion by moving the nut, which moves a linear distance equals to $1.5 \mathrm{~mm}$ when the screw thread turns one revolution (pitch), then the motion is transmitted to the movable platform through the motion arms and the two $U$ joints. The main parts of the mechanism are shown in Figure 5, where Figure 5(a) presents a schematic diagram. Figure 5(b) shows the U joint details.

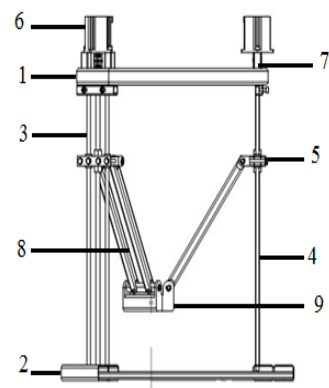

(a)

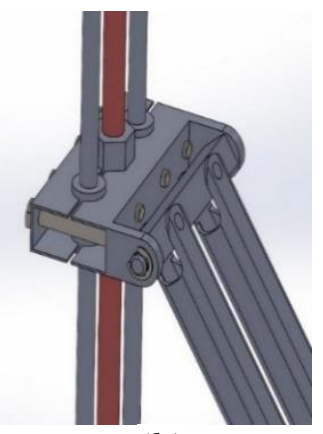

(b)
Figure 5: (a) Schematic diagram of the proposed mechanism, (b) $\mathrm{U}$ joint.

1. Frame top base, 2. Frame bottom base, 3 . Vertical parallel guide ways, 4 . Screw thread, 5. Nut, 6. Stepper motor, 7. Coupling, 8. Movement arm, 9. Movable platform.

\section{Mechanism design in Solidworks 4.1. Solidworks outline}

Design programs such as (Solidworks, Solid edge, NX (Unigraphics), Pro engineer, inventor, CATIA, etc.), are widely spread because of ease of use, availability, and scheduling of raw materials that are useful in design and the many features that they have. Solidworks is used in designing and simulating mechanical systems [28], it enables creators to outline out thoughts, explore different avenues regarding highlights, and 3D model production. It starts with paper sketches followed by Solidworks environment to construct the parts and assemble them together. 2D drawings are the last stage then the design can be sent to be manufactured. These significant stages are shown in Figure 6 [29], [30].

\subsection{Three-dimensional mechanism designation}

Planning steps are following the stream outline in Figure 6. As a matter of first importance, choosing the elements of each part to turn out with appropriate design area. Then, demonstrating the parts separately, this developed mechanism is separated to three main group; Main frame (fixed bottom base, fixed top base, and vertical pillars), the screw drive group (stepper motor, coupling, screw drive, moving nut), and the movable platform group (movable platform, and motion arms with two U joints), Figure 7(a) shows the main groups of the structure. Subsequent stage is to consolidate parts to manufacture the last structure. A down-up strategy is utilized, which begins by building the parts and joining them. Figure 7(b) presents structure assembly.

\subsection{Working area and dimensions}

Dimensions of the mechanism are proposed based on the operating dimensions of portable $\mathrm{CNC}$ machines that depends on the required working area, so that the movement of the table should cover the required space based on the required function. The working area is the area in which the machine can reach and operates. After completing the design in the Solidworks, the machine performance was tested to ensure that the required work area can be covered, as shown in Figure 8. From workspace results of the experimental tests on the Solidworks program, it can be noted that the model of the Portable CNC machine as shown in Figure 8 can work in a specific area that cannot be bypassed. In this area the machine can perform any type of operation such as (hole, formation of any path or opening of the sewerage ... etc.).

\subsection{Finite element analysis}

Static analysis was employed on the frame of the mobile CNC machine to check its ability to stand under the working loads such as the cutting force. Stress, strain, displacement, and factor of safety were checked for Steel and Aluminum materials. Table 1 shows the materials specifications. The following procedures were followed to check from not to collapse, the installations were performed in three green locations, the loading area was the moving table, which is the mounting area for the tools (purple locations), as shown in Figure 9. The Steel frame mass was about $16.5 \mathrm{~kg}$, while the aluminum frame mass was $5.641 \mathrm{Kg}$. An external weight of $60 \mathrm{~kg}$ is applied to frame through the static analysis.

Table 1: Material specifications [31], [32]

\begin{tabular}{|c|c|c|c|}
\hline Property & Unit & $\begin{array}{c}\text { AISI 1035 } \\
\text { Steel (SS) }\end{array}$ & $\begin{array}{c}\text { Aluminum } \\
1 \cdot \uparrow \cdot \text { Alloy }\end{array}$ \\
\hline $\begin{array}{c}\text { Elastic } \\
\text { Modulus }\end{array}$ & $\mathrm{N} / \mathrm{m}^{2}$ & $2.05 \mathrm{e}+11$ & $6.9 \mathrm{e}+10$ \\
\hline $\begin{array}{c}\text { Poisson's } \\
\text { Ratio }\end{array}$ & $\mathrm{N} / \mathrm{A}$ & 0.29 & 0.33 \\
\hline $\begin{array}{c}\text { Shear } \\
\text { Modulus }\end{array}$ & $\mathrm{N} / \mathrm{m}^{2}$ & $8 \mathrm{e}+10$ & $2.7 \mathrm{e}+10$ \\
\hline $\begin{array}{c}\text { Mass Density } \\
\text { Tensile } \\
\text { Strength }\end{array}$ & $\mathrm{Kg} / \mathrm{m}^{3}$ & 7850 & 2700 \\
\hline $\begin{array}{c}\text { Yield } \\
\text { Strength }\end{array}$ & $\mathrm{N} / \mathrm{m}^{2}$ & 585000003 & 68935600 \\
\hline $\begin{array}{c}\text { Thermal } \\
\text { Expansion } \\
\text { Coefficient }\end{array}$ & $\mathrm{K}$ & $1.1 \mathrm{e}-05$ & $2.4 \mathrm{e}-05$ \\
\hline $\begin{array}{c}\text { Thermal } \\
\text { Conductivity }\end{array}$ & $\mathrm{W} /(\mathrm{m} \cdot \mathrm{K})$ & 52 & 200 \\
\hline $\begin{array}{c}\text { Specific Heat } \\
\text { Then }\end{array}$ & $\mathrm{J} /(\mathrm{kg} \cdot \mathrm{K})$ & 486 & 900 \\
\hline \multicolumn{2}{|l|}{} \\
\hline
\end{tabular}




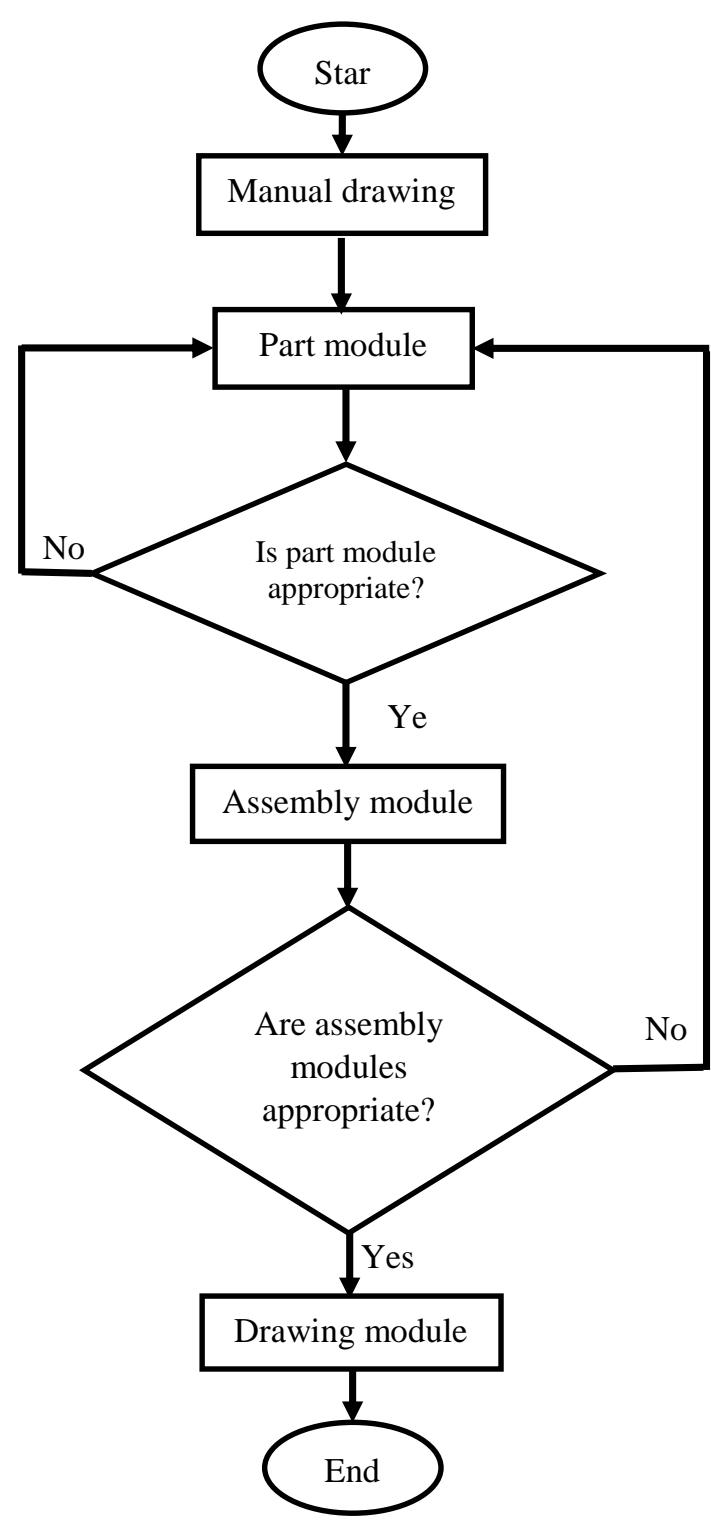

Figure 6: Design steps in SolidWorks, reproduced from

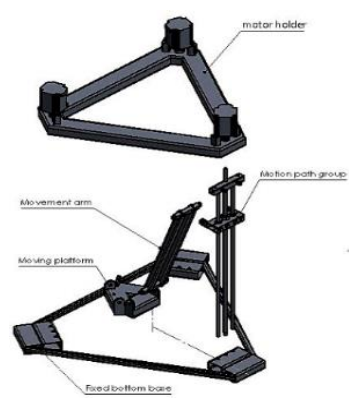

(a)

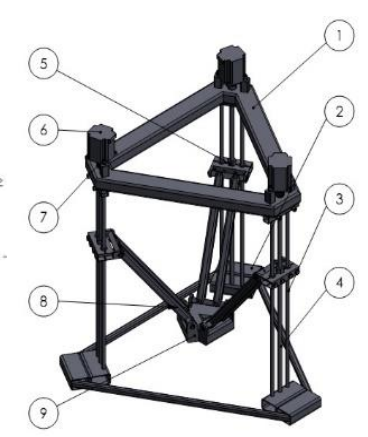

(b)
Figure 7: (a) Parts of subassemblies of the structure, (b) The full structure assembly. 1. Frame top base, 2. Frame bottom base, 3. Vertical pillars, 4. Screw thread, 5. Nut, 6. Stepper motor, 7. Coupling,

8. Motion arm. 9. Movahle nlatform.

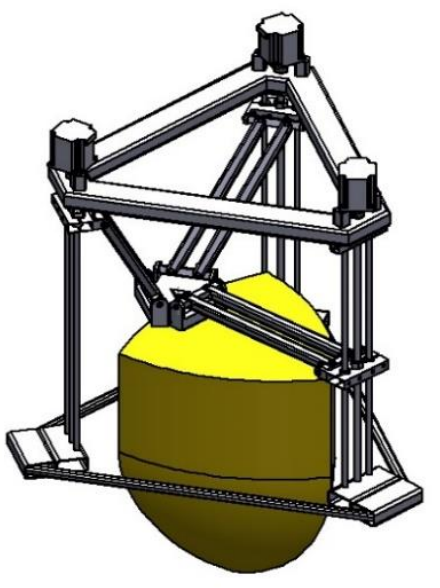

(a)

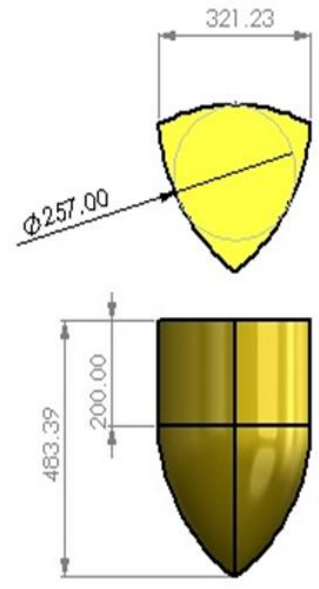

(b)
Figure 8: (a) Mechanism working area, and (b) Dimensions of working area ( $\mathrm{mm})$

\subsection{Steel frame Finite element analysis}

FEA of the steel frame for (stress, strain, displacement, and factor of safety) was shown in Figure 9, the maximum stress value was $6.117 \mathrm{e}+7 \mathrm{~N} / \mathrm{m} 2$, while the minimum value was $1.371 \mathrm{e}+01 \mathrm{~N} / \mathrm{m} 2$, the maximum stress was much fewer than the yield strength $(2.827 \mathrm{e}+8 \mathrm{~N} / \mathrm{m} 2)$, so the part will stand for external loads, the maximum value was at the upper support, the Screw, and shaft since it was the part that absorbed the reaction of the applied force or pressure transmitted by means of screw, the minimum stress value was at the base as in Figure 9 (a). The maximum strain was $1.312 \mathrm{e}-04$ at the upper support, the screw, and shaft since it was the part that absorbed the reaction of the applied force or pressure transmitted by means of screw, as in Figure 9 (b), and the maximum deformation was small $(0.1576 \mathrm{~mm})$, the maximum value was at in the upper arm, as shown in Figure 9 (C). Considering the safety factor test; it was obvious that the frame was save as shown in Figure 9 (d) (blue colored area), and the minimum factor of safety was 4.6.

Mesh information and details for the mobile CNC machine static simulation is shown in Table 2 and Table 3.

Table 2: Mesh information

\begin{tabular}{|c|c|}
\hline Mesh type & Solid Mesh \\
\hline Mesher Used: & Curvature-based mesh \\
\hline $\begin{array}{c}\text { Jacobian points for High } \\
\text { quality mesh }\end{array}$ & 16 Points \\
\hline Maximum element size & $46.519 \mathrm{~mm}$ \\
\hline Minimum element size & $9.3038 \mathrm{~mm}$ \\
\hline Mesh Quality & High \\
\hline $\begin{array}{c}\text { Remesh failed parts with } \\
\text { incompatible mesh }\end{array}$ & Off \\
\hline
\end{tabular}



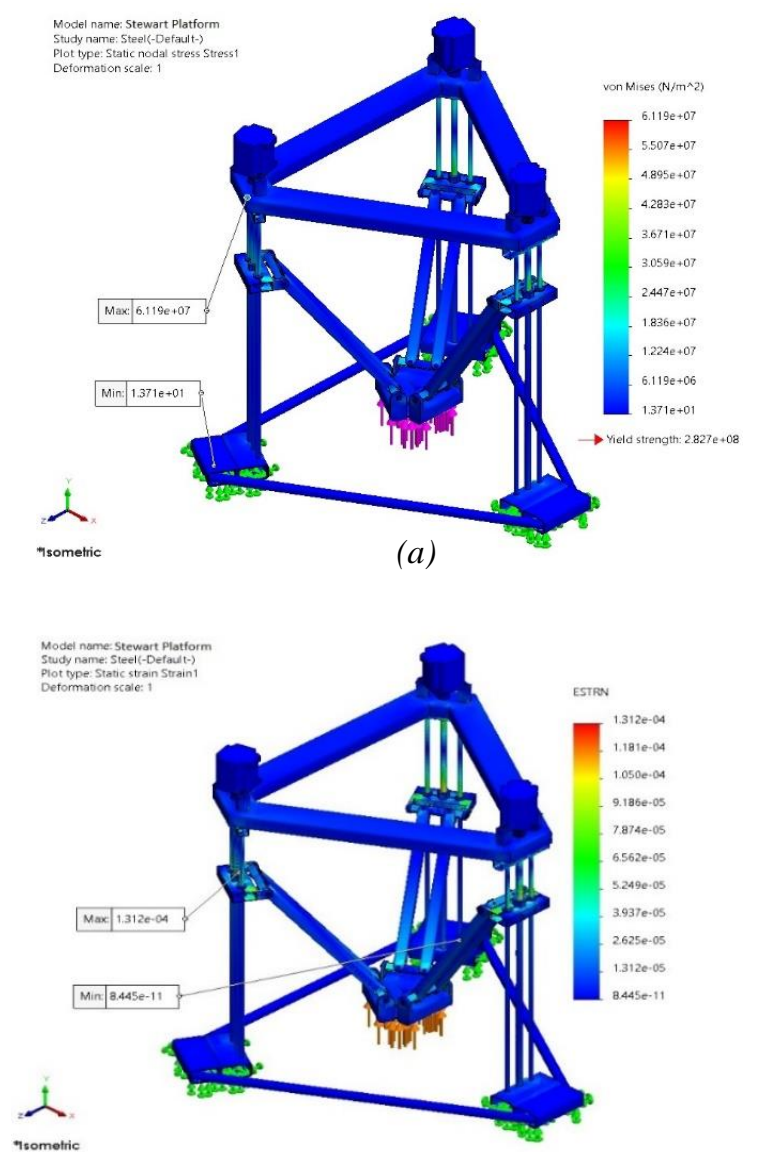

(b)

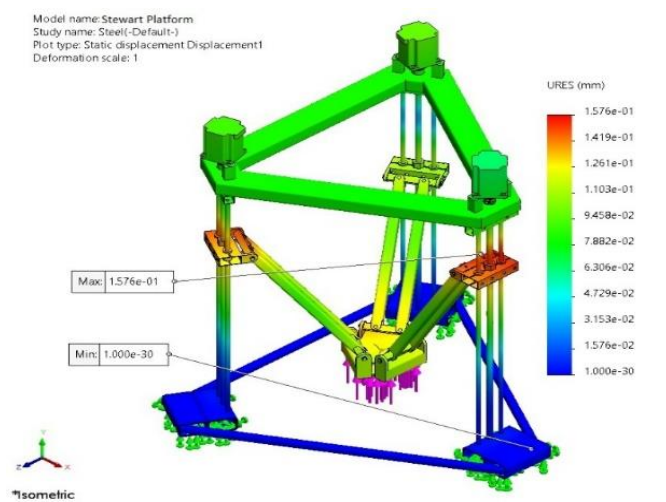

(c)

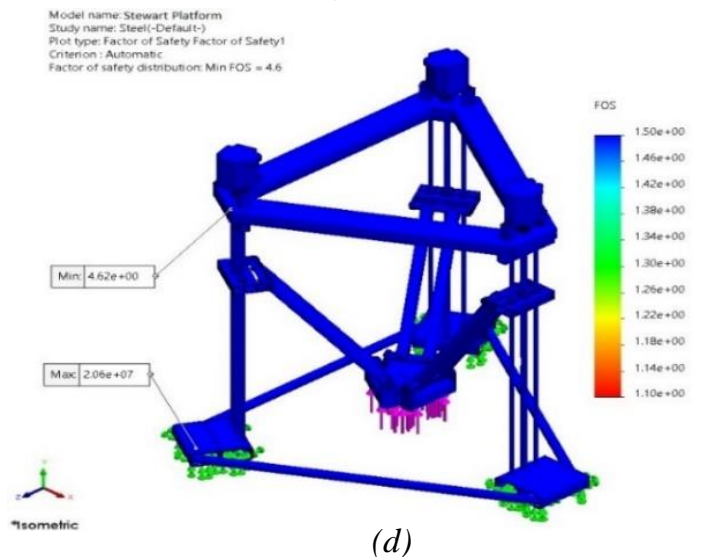

Figure 9: Steel (a) Stress test, (b) Strain test, (c) Displacement test, and (d) Factor of safety test.
Table 3: Mesh information - Details

\begin{tabular}{|c|c|}
\hline Total Nodes & 222198 \\
\hline Total Elements & 113011 \\
\hline Maximum Aspect Ratio & $1,397.2$ \\
\hline$\%$ of elements with Aspect Ratio < 3 & 34.8 \\
\hline$\%$ of elements with Aspect Ratio > 10 & 8.24 \\
\hline \% of distorted elements (Jacobian) & 0 \\
\hline
\end{tabular}

\subsection{Aluminum frame Finite element analysis}

FEA of the Aluminium frame for (stress, strain, displacement, and factor of safety) was shown in Figure 10 , the maximum stress value was $5.868 \mathrm{e}+7 \mathrm{~N} / \mathrm{m} 2$, while the minimum value was $1.371 \mathrm{e}+01 \mathrm{~N} / \mathrm{m} 2$, the maximum stress was higher than the yield strength $(2.757 \mathrm{e}+7 \mathrm{~N} / \mathrm{m} 2)$, so the part will not stand for external loads, the maximum value was at the upper support, the Screw, and shaft since it was the part that absorbed the reaction of the applied force or pressure transmitted by means of screw, the minimum stress value was at the base as in Figure 10 (a). The maximum strain was 3.99 e-04 at the upper support, the screw, and shaft since it was the part that absorbed the reaction of the applied force or pressure transmitted by means of screw, as in Figure 10 (b), and the maximum deformation was large $(0.467 \mathrm{~mm})$, the maximum value was at in the upper arm, as shown in Figure 10 (C). Considering the safety factor test; it was obvious that the frame was unsafe as shown in Figure 10 (d) (red colored area), and the minimum factor of safety was 0.47 that is less than one, meaning that Aluminum frame design is unsafe.

Mesh information and details for the mobile CNC machine static simulation is shown in Table 4 and Table 5.

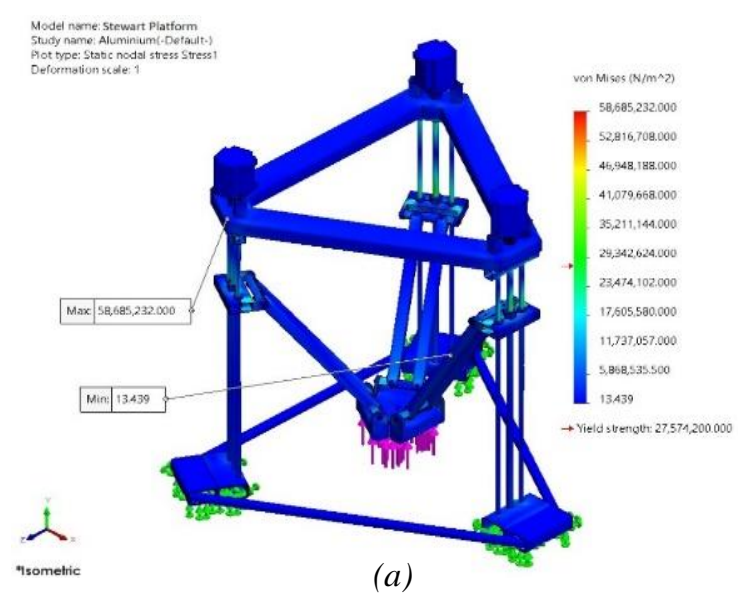




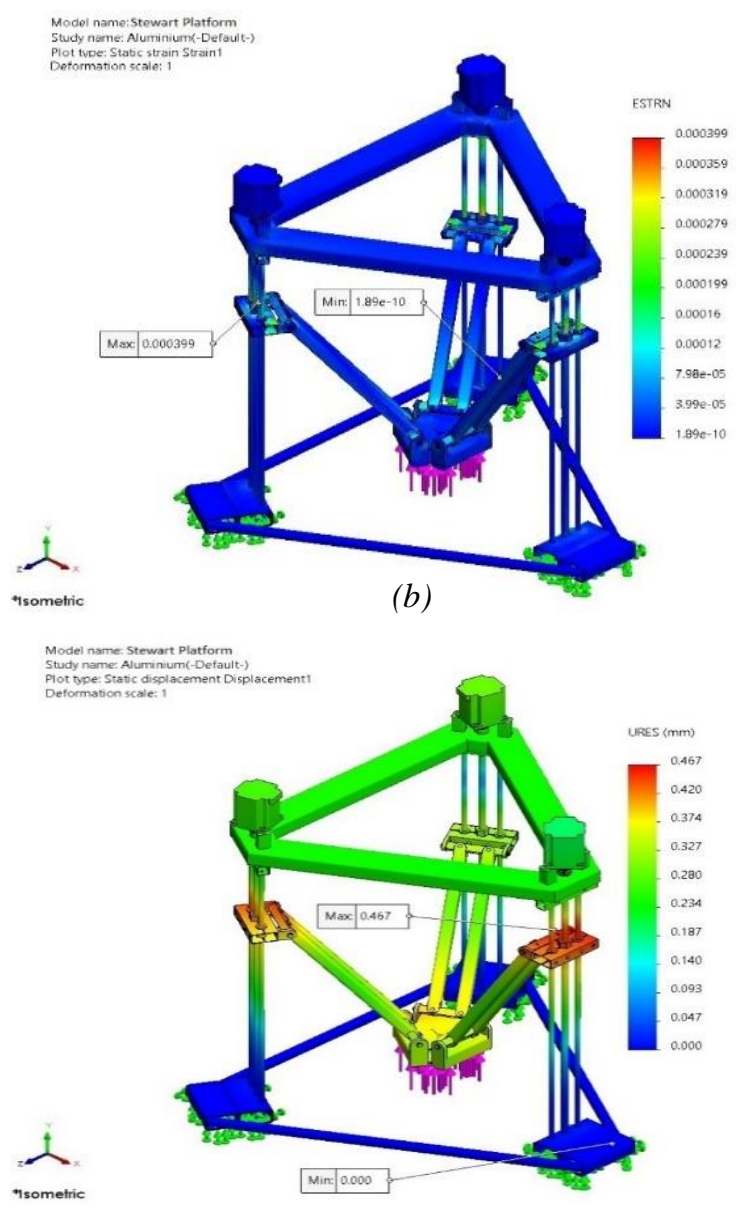

(c)

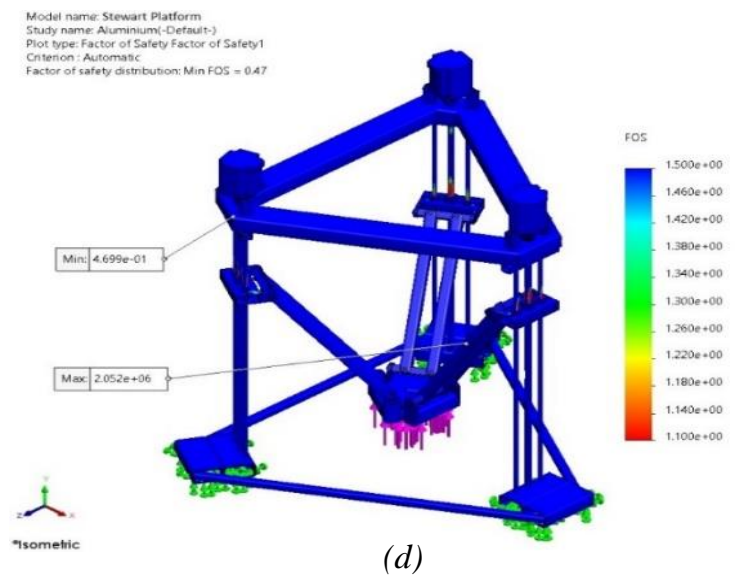

Figure 10: Aluminum: (a) Stress test, (b) Strain test, (c) Displacement test, (d) Factor of safety test

Table 4: Mesh information

\begin{tabular}{|c|c|}
\hline Mesh type & Solid Mesh \\
\hline Mesher Used: & Curvature-based mesh \\
\hline $\begin{array}{c}\text { Jacobian points for High } \\
\text { quality mesh }\end{array}$ & 16 Points \\
\hline Maximum element size & $46.519 \mathrm{~mm}$ \\
\hline Minimum element size & $9.3038 \mathrm{~mm}$ \\
\hline Mesh Quality & High \\
\hline $\begin{array}{c}\text { Remesh failed parts with } \\
\text { incompatible mesh }\end{array}$ \\
\hline
\end{tabular}

Table 5: Mesh information - Details

\begin{tabular}{|c|c|}
\hline Total Nodes & 222198 \\
\hline Total Elements & 113011 \\
\hline Maximum Aspect Ratio & $1,397.2$ \\
\hline \% of elements with Aspect Ratio < 3 & 34.8 \\
\hline \% of elements with Aspect Ratio > 10 & 8.24 \\
\hline \% of distorted elements (Jacobian) & 0 \\
\hline
\end{tabular}

\subsection{Material selection}

In addition to failure of Aluminum frame in some points, and the maximum stress is nearly the same in both cases of Steel and Aluminum, but the yield strength and factor of safety are much higher in Steel case compared to Aluminum case. However, the strain and deformation values under the same load are much smaller in case of Steel as well. Hence, Steel material is selected.

\section{THE REVERSE KINEMATICS PROBLEM}

Parallel manipulators are often classified according to the number of connections between the fixed bottom (base) and the upper platform. In this model the base (link1) and the platform (link2) are connected by means of 6 intermediate links (a2, a3), all links connected together by means of 6 universal joints each has 2 DOF and 3 prismatic joints, each has 1 DOF with independent joint constraints. The model degree of freedom then can be calculated using Grubler's formula which results model DOF equal to 3 as in equation (1).

DOFs $=\mathrm{m}(\mathrm{N}-1-\mathrm{J})+\sum_{i=1}^{J} f_{i}$

Where

$\mathrm{N}$ : \# of links including ground,

$\mathrm{J}$ : \# of joints,

$\mathrm{m}=6$ for spatial bodies,

f: \# of freedoms allowed by joints.

Parallel manipulator almost faces trivial problems in inverse kinematics analysis and is much easier than forward kinematics. The reverse kinematics relations for a 3DOF machine platform can be mathematically formulated in several ways. Every representation of the problem can have its advantages and disadvantages which become emphasized when a different optimization algorithm is applied. The inverse kinematics solution in this work is based on the determination of the structural parameters of the parallel manipulator, when the position and orientation of the movable platform are given to solve the input displacement of the prismatic joints.

The most common set of parameters in inverse kinematics are: joint position vectors on base and mobile platform $(\overrightarrow{a 1}$ and $\vec{b}$ ), translation vectors between base and mobile systems $(\vec{S}$ and $\vec{P})$, radii of fixed and movable platforms $(\mathrm{R}, \mathrm{r})$, distance between closes parallel guide ways ( $a 2$ and a3), joint placement defined with no rotation angle between joints for both platforms Figure 11 and joint 
moving area $\left(R_{1}^{0}=\mathrm{I}\right.$, unit matrix). From those values are then calculated values for joints movable leg length (motor element) $\overrightarrow{S 1}$ which are used in calculations to control the position of movable end effector (tool) that placed on mobile platform above the geometrical center of joints at required $\mathrm{X} 1, \mathrm{Y} 1$ and $\mathrm{Z} 1$ position (see equations (2), (3) and (4)).
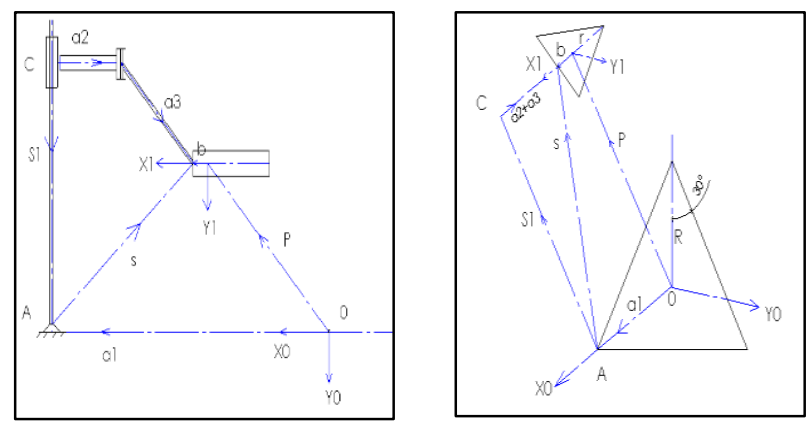

Figure 11: Inverse kinematics vectors analysis geometric parameters.

End effector (tool) is placed on mobile platform above the geometrical center of joints placed on that platform by height tool. Therefore, the inverse position kinematics solves the input tool position variables $\vec{P}=[\mathrm{x} 1, \mathrm{y} 1, \mathrm{z} 1]$ from a given output actuated motor position value $\vec{S}$.

$\overrightarrow{S 1}+\vec{S}=\overrightarrow{a 2}+\overrightarrow{a 3}$

$\overrightarrow{a 1}+\vec{S}=\vec{P}+R_{1}^{0} \vec{b}$

From (2) and (3);

$\overrightarrow{S 1}=-\vec{P}-R_{1}^{0} \vec{b}+(\overrightarrow{a 1}+\overrightarrow{a 2}+\overrightarrow{a 3})$

Where,

$$
\begin{aligned}
& \overrightarrow{a 1}=\left[\begin{array}{lll}
\mathrm{R} & 0 & 0
\end{array}\right] \mathrm{T}, \\
& \overrightarrow{a 2}=[(\mathrm{R}-a 2)-\mathrm{R} \quad 0 \quad 0] \mathrm{T} \text {, } \\
& \overrightarrow{a 3}=[((\mathrm{x} 1+\mathrm{r} \sin 30)-(\mathrm{R}-a 2))(\mathrm{y} 1-\mathrm{yc}) 0] \mathrm{T} \text {, }
\end{aligned}
$$

$\vec{P}=\left[\begin{array}{lll}\mathrm{x} 1 & \mathrm{y} 1 \mathrm{z} 1\end{array}\right] \mathrm{T}$,

$\vec{b}=[(\mathrm{x} 1+\mathrm{r}) \mathrm{y} 10] \mathrm{T}$,

$R_{1}^{0}=\mathrm{I}$, unit matrix

Python software was applied to some computational relationships for different platform planner positions $\vec{P}$ and program was worked correctly (Figure 12, and 13).

The change in the movable leg length (motor element)

$\Delta S 1$ can be calculated as;

$\Delta S 1=N * P$

Where,

$N$ :Number of motor revolutions in minutes (rev/min).

$P$ : Thread pitch (mm).

Then the movable platform position can be controlled based on the change in movable leg length $\Delta S 1$, or motor $\mathrm{rev} / \mathrm{min}$, or motor input torque $\tau$, as motor torque is a function in motor revolution per minutes.

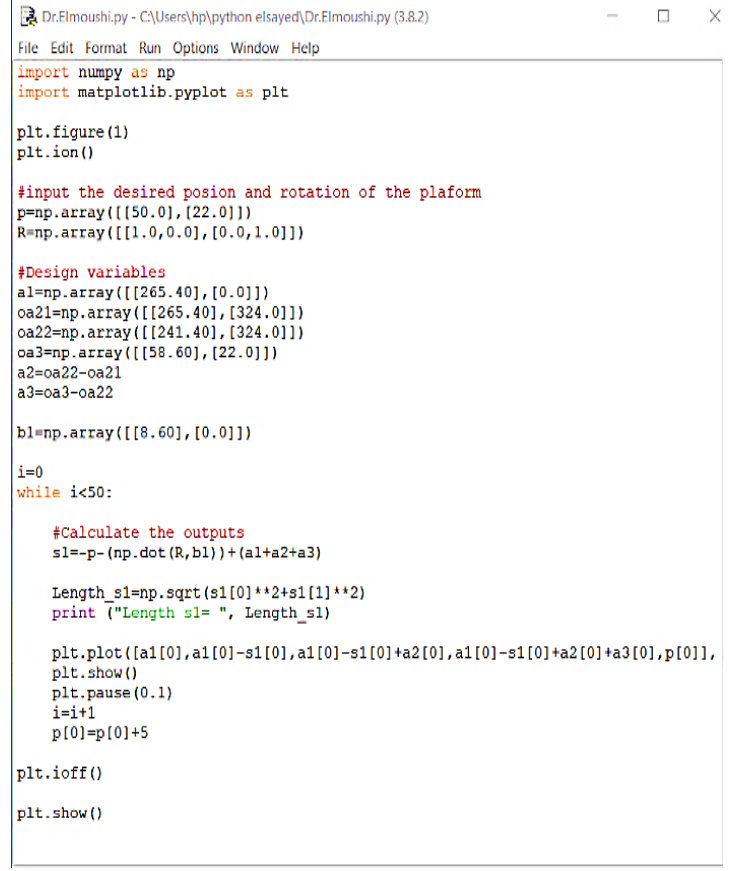

Figure 12: Python software program output results for movable leg length $\overrightarrow{S 1}$.

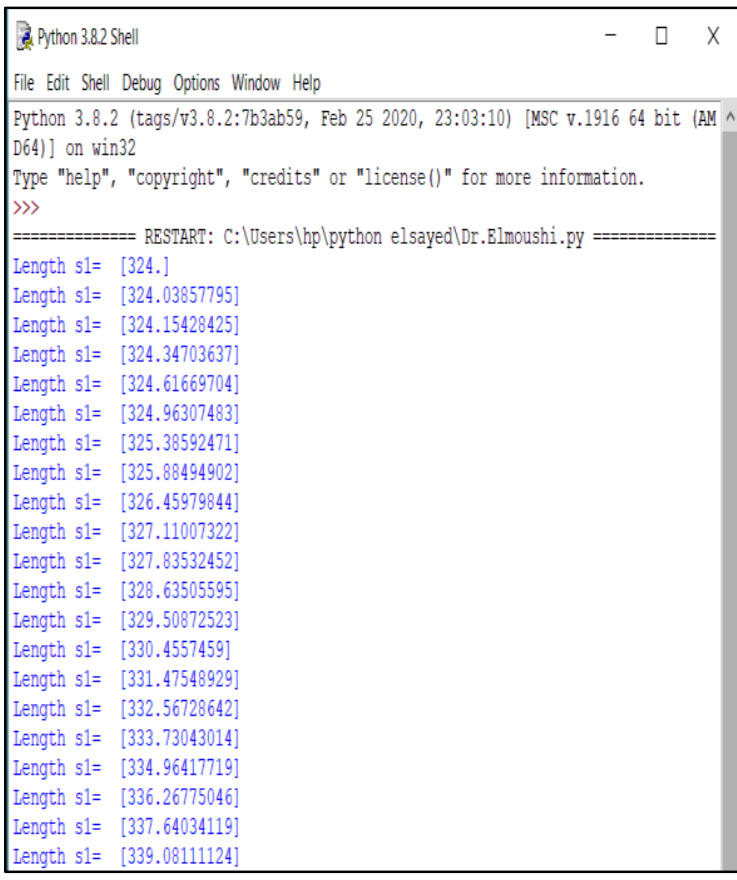

Figure 13: Python software program for movable leg length $\overrightarrow{S 1}$ calculation on the basis of joint parameters.

\section{SIMULINK MODEL DEVELOPMENT AND DYNAMICS SIMULATION}

Simulink ${ }^{\circledR}$ is a software package for modeling, simulating, and analyzing dynamic systems. It supports linear and nonlinear systems, modeled in continuous time, sampled 
time, or a hybrid of the two. Systems can also be multirate, i.e., have different parts that are sampled or updated at different rates. Simulations are interactive, and an instant access to all the analysis tools in MATLAB ${ }^{\circledR}$ is available, so the results can be analyzed and visualized immediately. Simulink is also practical as modeling and solving real problems can take place. Simulink is a well tool for model-based design [33].

\subsection{Simulink model}

The developed mechanism in Solidworks in this work is transferred into Simulink software in the form of Simulink model that contains blocks, in order to perform simulation for design verification. The blocks imported to the Simulink were rearranged according to the engineering laws, the physical laws, and the required assembly. The Simulink model contains three blocks; these are the inputs, the system, and the outputs blocks. The input block shows three inputs; these are the torque required to power each screw thread. The output block represents the three outputs value which are the $\mathrm{X}, \mathrm{Y}$, and $\mathrm{Z}$ position of the movable platform. The system block shows the model of the portable CNC machine structured in Simulink blooks.

\subsection{Open loop dynamics}

Simulation experiments are performed to check system dynamics. In the First experiment; the motors are given certain number of rev/min and rotation direction then the movable platform position is measured. In the second experiment the motors are given certain torque signal then the movable platform position is measured.

\subsubsection{Experiment 1}

First, the three motors are moved with the same rev/min in counterclockwise and the position of the movable platform in $\mathrm{X} \mathrm{Y} \mathrm{Z} \mathrm{directions} \mathrm{is} \mathrm{measured} \mathrm{the} \mathrm{movable}$ platform moved in the $Y$ direction only as shown in Figure 14. Second, the motors M1 and M2 are rotated with the same rev/min in clockwise direction, and the position of the movable platform in $\mathrm{X}, \mathrm{Y}$, and $\mathrm{Z}$ directions is measured. The movable platform moved in the $\mathrm{Y}, \mathrm{X}$ and $\mathrm{Z}$ directions as shown in Figure 15. Third, the motor M1 is rotated counter-clockwise, and the position of the movable platform is measured in $\mathrm{X}, \mathrm{Y}$, and $\mathrm{Z}$ directions. The movable platform moved in the $\mathrm{X}$, and $\mathrm{Y}$ directions as shown in Figure 16.

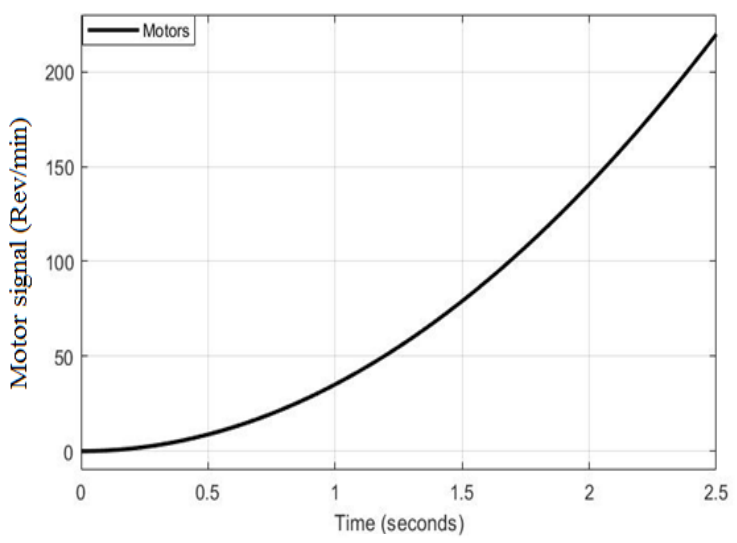

(a)

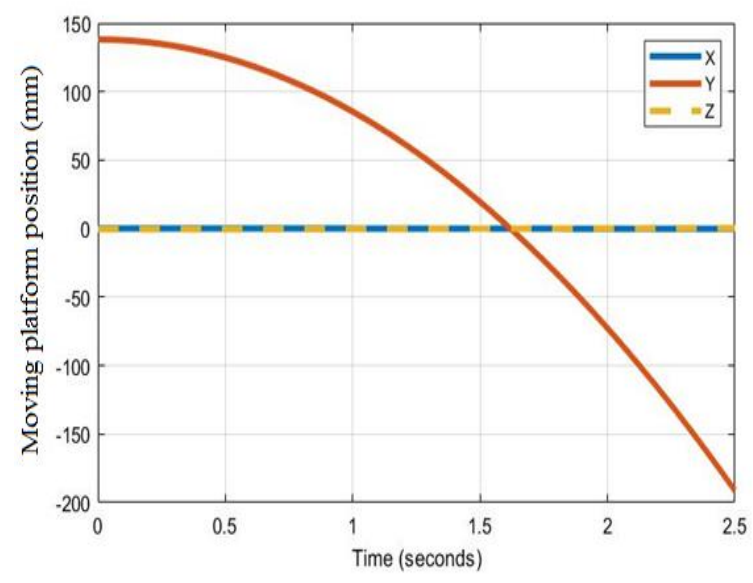

(b)

Figure 14:(a) Rev/min of the three motors, (b)Position of movable platform in $\mathrm{X}, \mathrm{Y}$, and $\mathrm{Z}$ directions

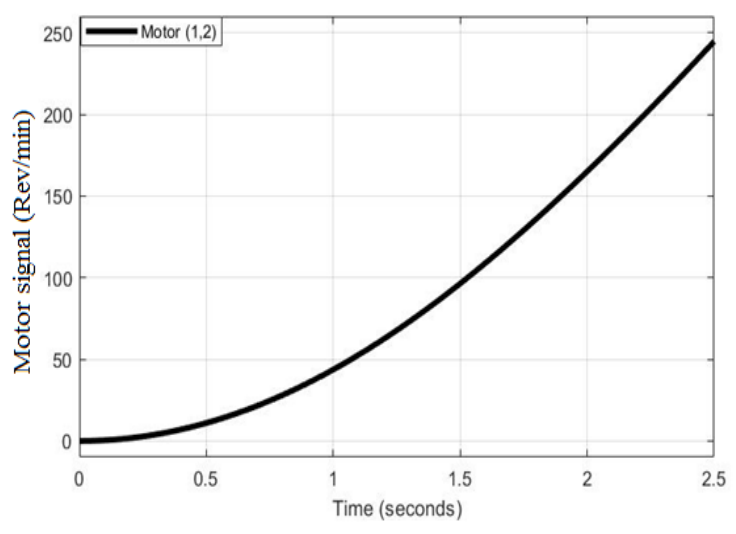

(a) 


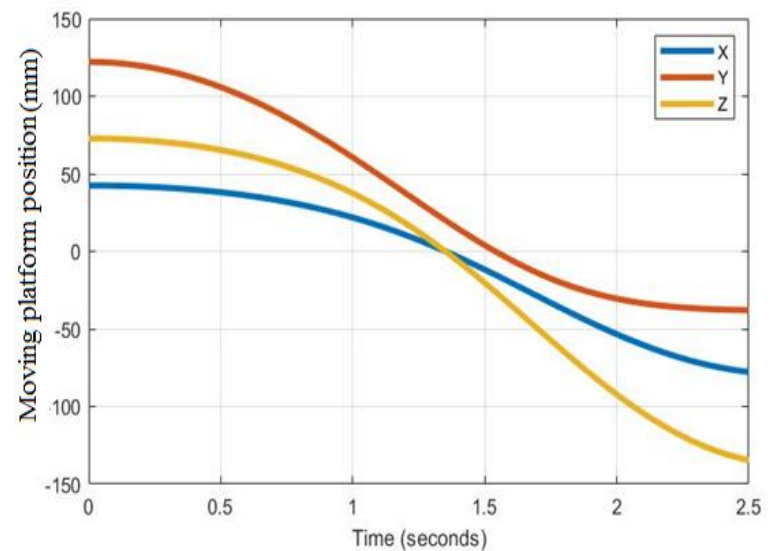

(b)

Figure 15:(a) Rev/min of motors 1 and 2, (b)

Position of movable platform in $\mathrm{X}, \mathrm{Y}$, and $\mathrm{Z}$ directions

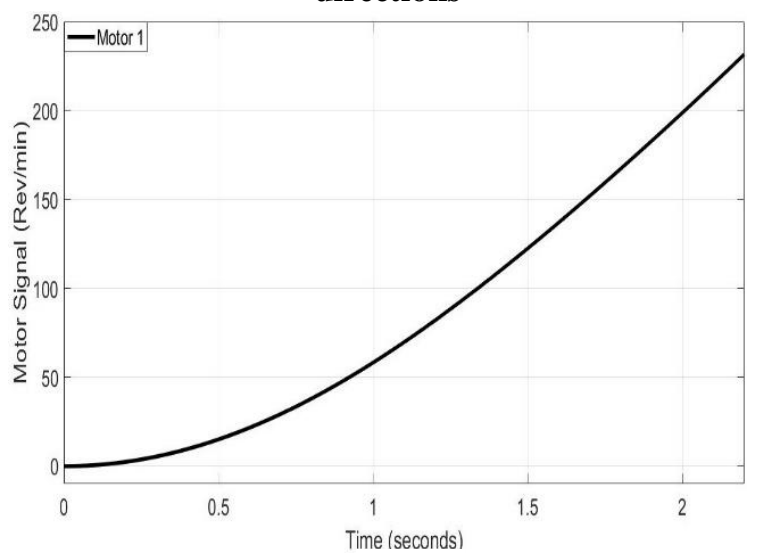

(a)

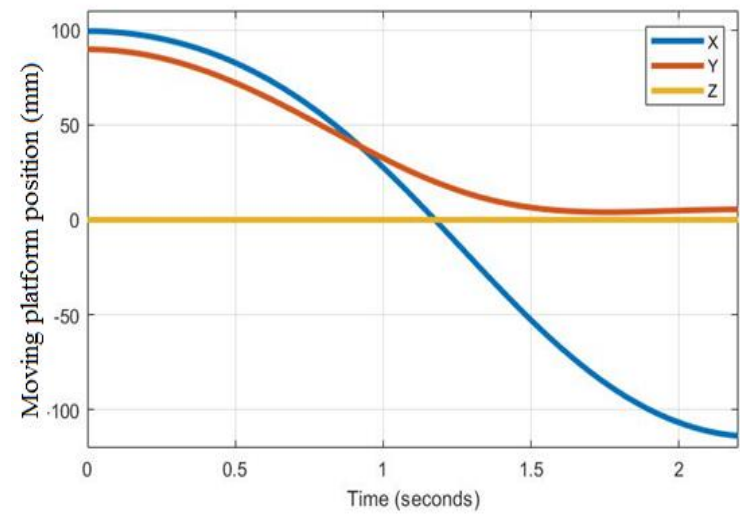

(b)

Figure 16: :(a) Rev/min of motor 1, (b) Position of movable platform in $\mathrm{X}, \mathrm{Y}$, and $\mathrm{Z}$ directions

\subsubsection{Experiment 2}

First, a torque signal is given to the motors and the location of the movable platform in directions (X Y Z) is measured without placing load in the opposite direction of motion, as shown in Figure 17. Second, an input torque is applied to the three motors with placing load in the opposite direction of motion of the movable Platform, as shown in Figure 18.

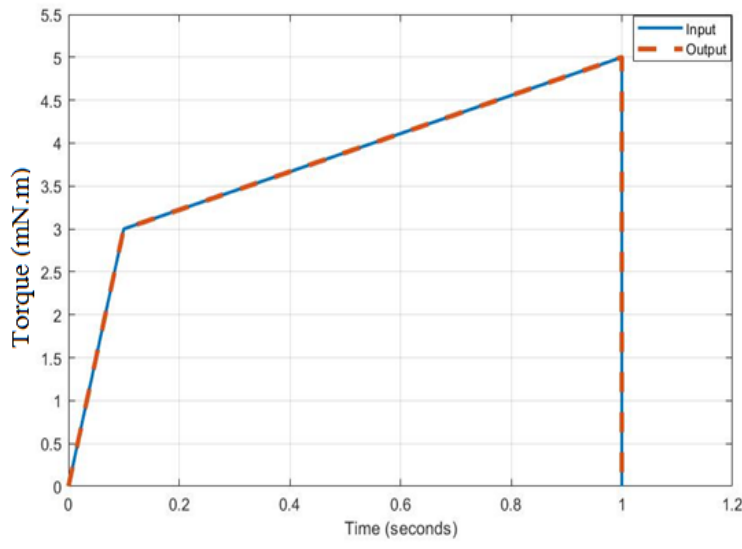

(a)

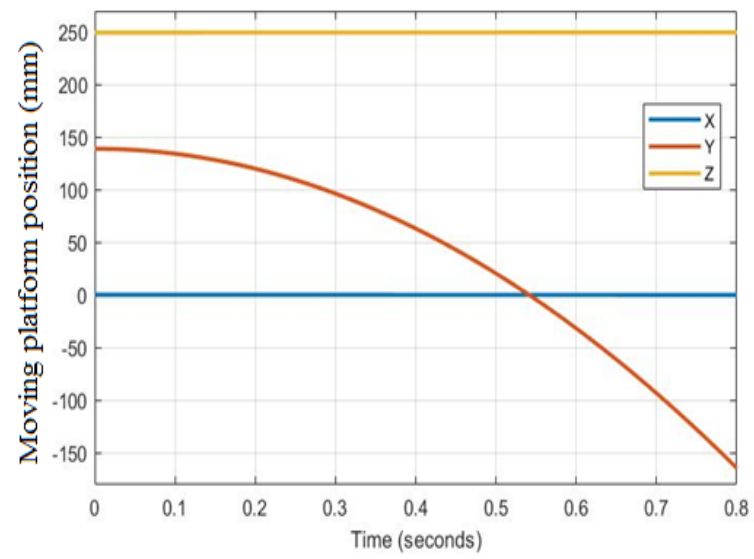

(b)

Figure 17: (a) Torque input of motors, (b) Movable platform position

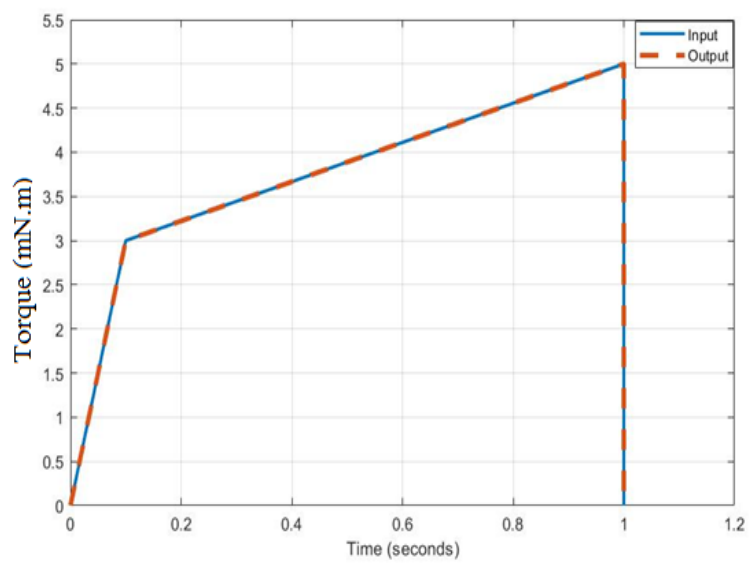

(a) 


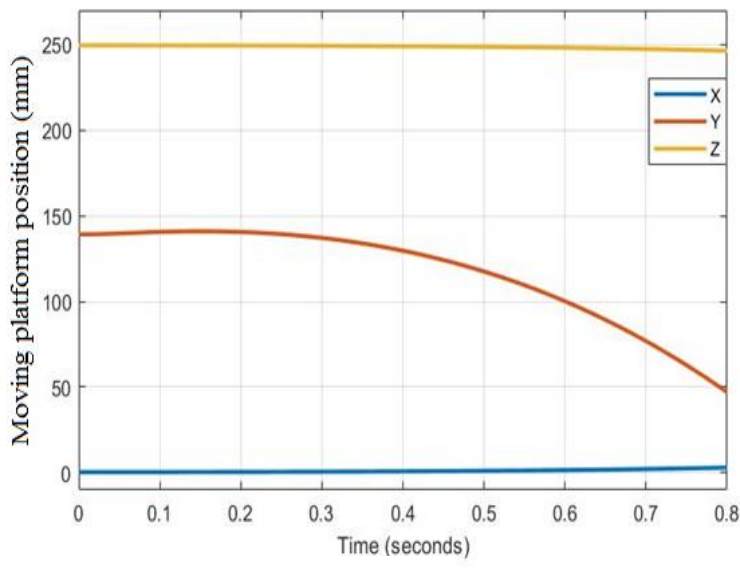

(b)

Figure 18: (a) torque input of motors, (b) Movable platform position.

\subsection{The Simulink model closed loop dynamics with PID controller}

A PID controller block is added to the Simulink model of the system. This PID controller block linearizes the system model, and the step response of the linearized plant is checked. Figure 19 shows the Simulink model with the PID controller. Figure 20 shows the controller characteristics and the step response.

Position input signal $(\mathrm{X}, \mathrm{Y}, \mathrm{Z})$ is sent to the movable platform, and the position output signal in $(\mathrm{X}, \mathrm{Y}, \mathrm{Z})$ are read. The path is given as shown in Figure 21.
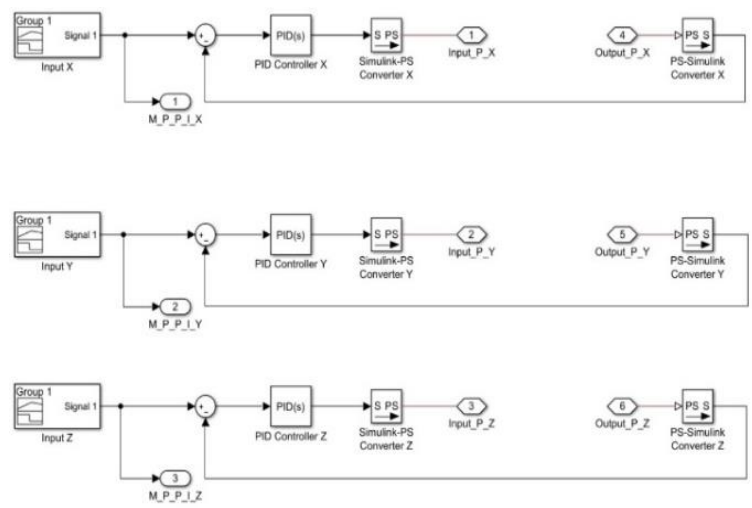

Figure 19: Simulink Model with PID controller

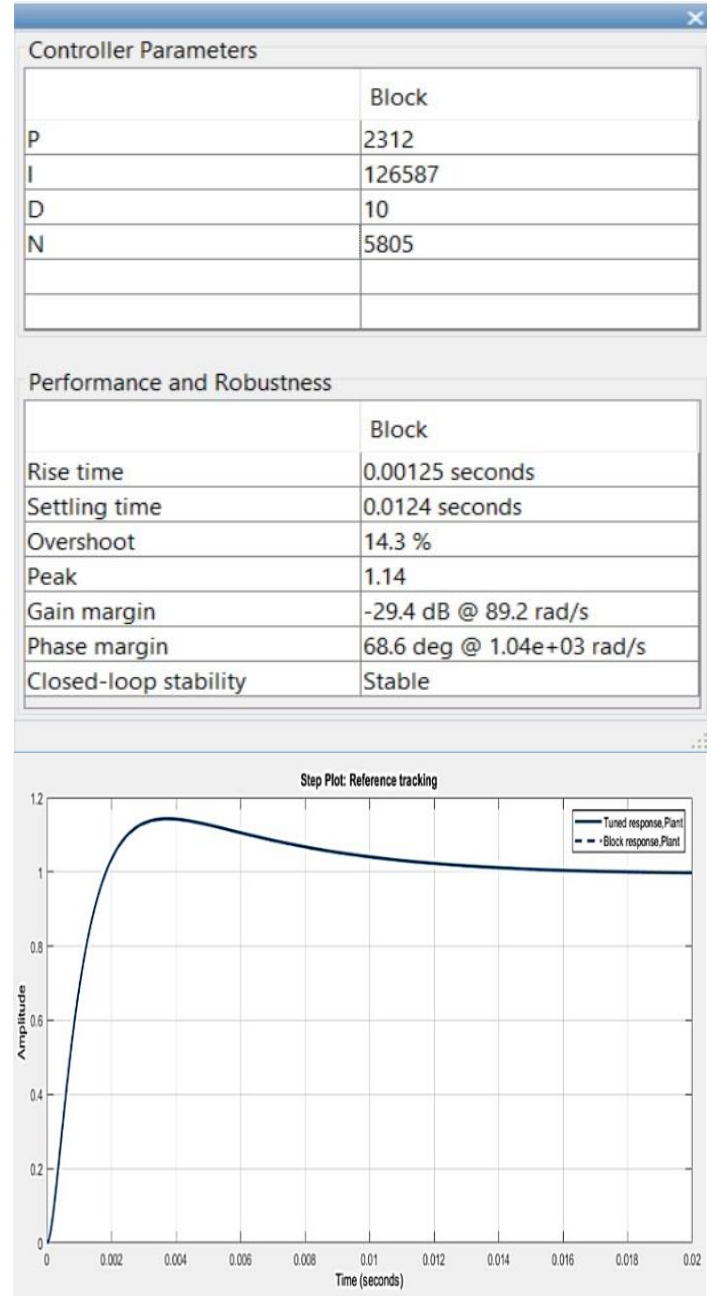

Figure 20: PID controller parameters and System step response.

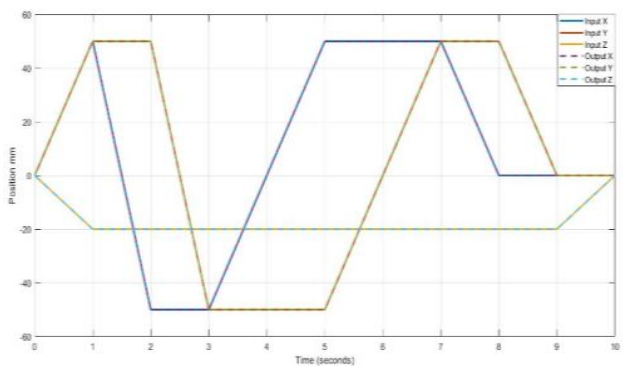

Figure 21: Movable platform position input and output

\section{MOBILE MACHINE PROTOTYPE} AND CONTROL CIRCUIT

After completing the design, all parts were manufactured as the result of the design and according to the sizes and materials described earlier. Figure 22 shows real photos of the mechanism prototype with the control box. Figure 23 presents a schematic diagram of the control circuit; Table 6 gives the specifications of control circuit components.

To test the robot; a flowchart that shows the required sequence of mechanism operating commands is shown in Figure 24, then full code illustration using Arduino software are given in Figure 25. 


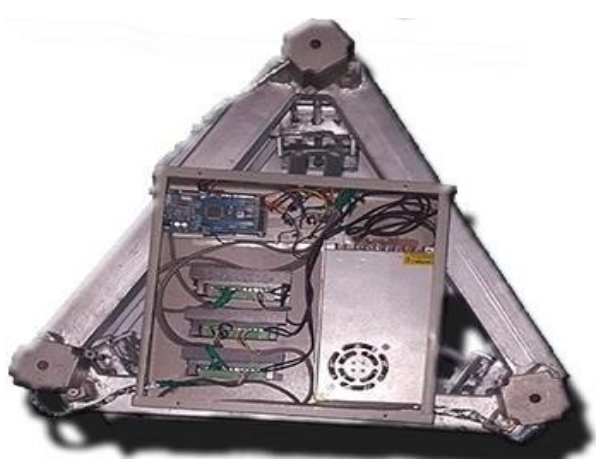

(a)

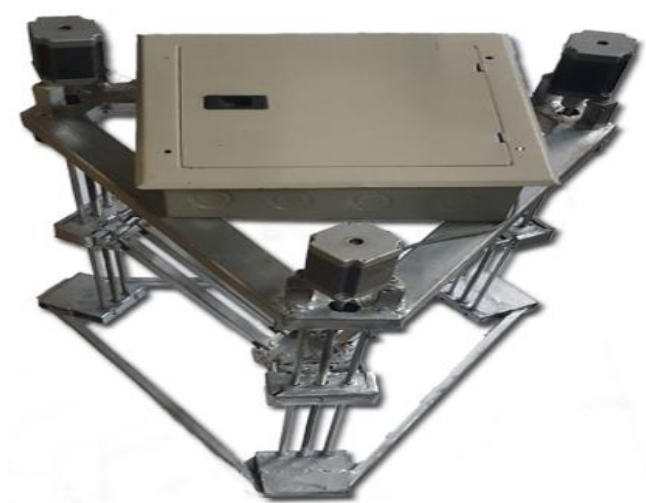

(b)

Figure 22: (a) and (b) Real photo of mechanism prototype with the control box opened and closed

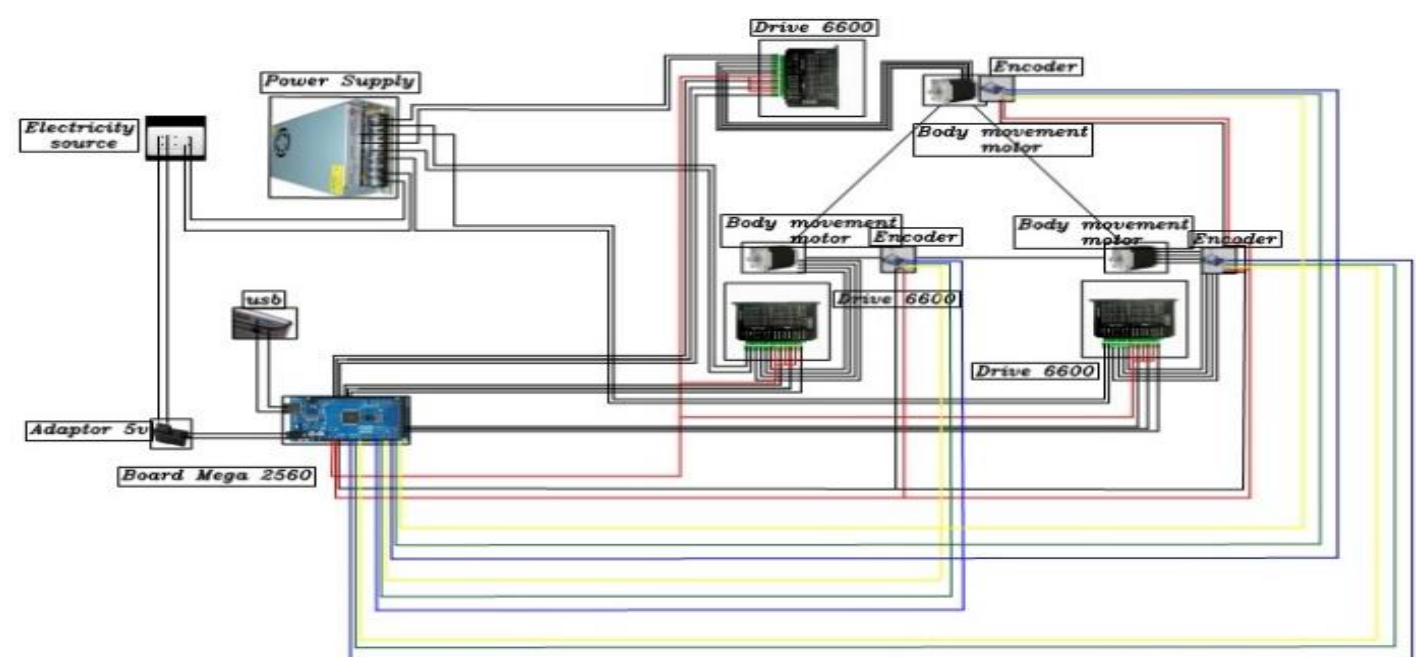

Figure23: Schematic diagram of control circuit

Error

Given a reference position for mobile table (Location X, $\mathrm{Y} \& \mathrm{Z})$
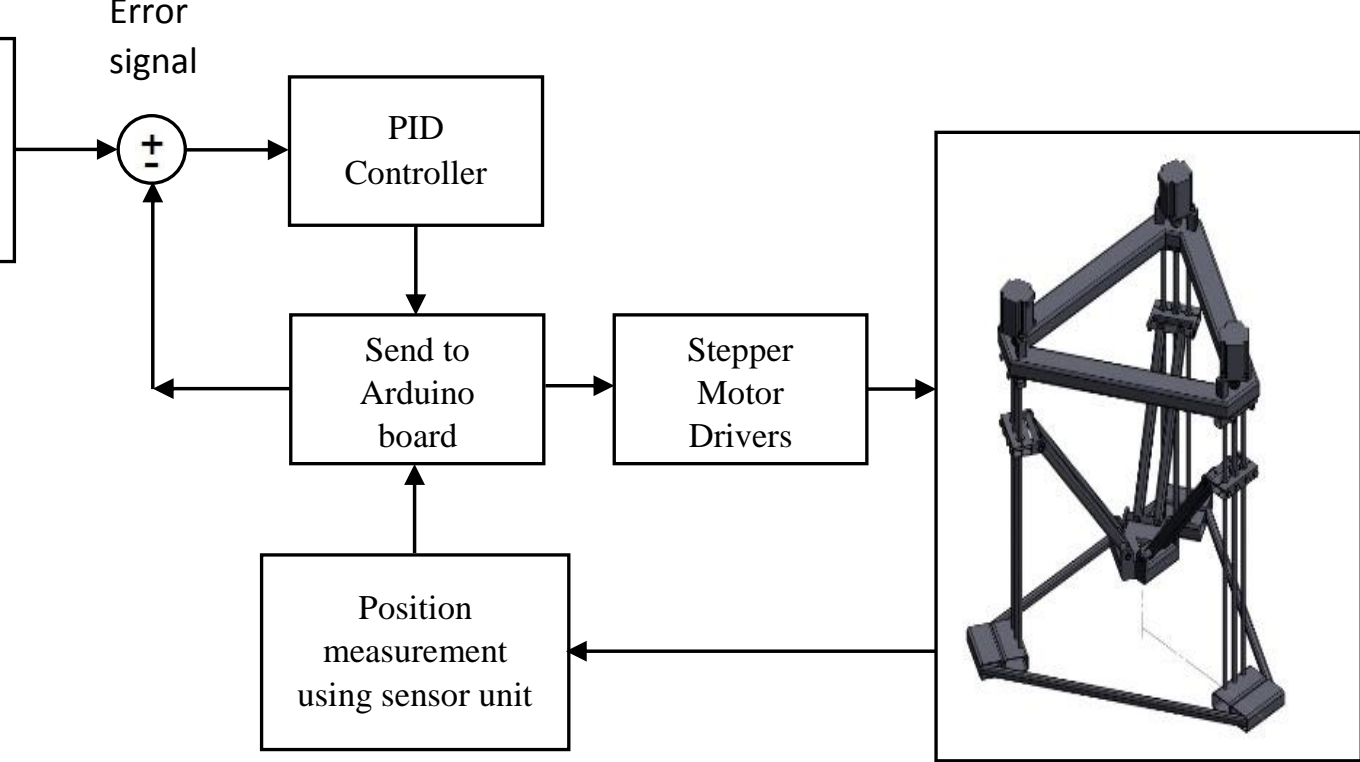

Figure 24: Flowchart of operating commands 
Table 6: Specifications of control circuit components

\begin{tabular}{|c|c|c|c|c|}
\hline No. & Part & No. of & Specifications & Function \\
\hline 1 & $\begin{array}{l}\text { Motor } \\
\text { Nema } 23\end{array}$ & 3 & $\begin{array}{l}\text { Torque: } 16 \mathrm{~kg} . \mathrm{cm} \\
\text { Current: } 2.9 \mathrm{~A} \\
\text { step angel: } 1.8 \\
\text { Motor speed: } 800 \text { r.p.m }\end{array}$ & $\begin{array}{l}\text {-Robot forward and } \\
\text { backward motion, } \\
\text {-Robot cleaning motion }\end{array}$ \\
\hline 2 & $\begin{array}{l}\text { Arduino } \\
\text { Mega } \\
2560 \\
\text { board }\end{array}$ & 1 & $\begin{array}{l}\text { A microcontroller board based on the AT mega } 2560 \text {, with } \\
54 \text { digital input/output pins (of which } 15 \text { can be used as } \\
\text { PWM outputs), } 16 \text { analog inputs, } 4 \text { UARTs (hardware } \\
\text { serial ports), a } 16 \mathrm{MHz} \text { crystal oscillator. }\end{array}$ & $\begin{array}{ll}\text { Control } & \text { program } \\
\text { development. } & \end{array}$ \\
\hline 3 & $\begin{array}{l}\text { Drive } \\
6600\end{array}$ & 3 & $\begin{array}{l}\text { TB6600 single axis 4A stepper motor driver controller 9- } \\
\text { 40V micro-step CNC power control sockets }\end{array}$ & $\begin{array}{l}\text { Contact the motor to the } \\
\text { control circuit }\end{array}$ \\
\hline 4 & $\begin{array}{l}\text { Power } \\
\text { supply }\end{array}$ & 1 & $12 \mathrm{DC}$ volt, $30 \mathrm{~mA}$ & DC power source \\
\hline 5 & $\begin{array}{l}\text { USB } 2.0 \\
\text { cable }\end{array}$ & 1 & Data transfer speed is $480 \mathrm{Mb} / \mathrm{sec}$ & $\begin{array}{l}\text { Connect the Arduino } \\
\text { board to PC. }\end{array}$ \\
\hline 6 & Adaptor & 1 & Input $100-240 \mathrm{~V}, 50 / 60 \mathrm{~Hz}, 0.2 \mathrm{~A}$ Output $5 \mathrm{~V}$ & $\begin{array}{l}\text { Connect the Arduino } \\
\text { board to power source }\end{array}$ \\
\hline
\end{tabular}

\section{$0 \leftrightarrow \square+1+$}

Stewart_Platform_Based_Movable_CNC_Mechanical_Design_and_Simula

lint ENA $=2$; //define Pulse pin Motor 1

int $\mathrm{DIR}=3 ;$ //define Direction pin Motor 1

int PUL=4; //define Enable Pin Motor 1

int ENA1 $=5 ; / /$ define Pulse pin Motor 2

int DIR1=6; //define Direction pin Motor 2

int puL1=7; //define Enable Pin Motor 2

int ENA2 $=8$; //define Pulse pin Motor 3

int DIR2=9; //define Direction pin Motor 3

int pUL2=10; //define Enable Pin Motor 3

void setup () i

pinMode (PUL, OUTPUT);

pinMode (DIR, OUTPUT);

PInMode (ENA, OUTPUT):

pinMode (PUL1, OUTPUT)

pinMode (DIR1, OUTPUT);

pinMode (ENA1, OUTPUT)

pinMode (PUL2, OUTPUT)

pinMode (DIR2, OUTPUT);

pinMode (ENA2, OUTPUT),

void loop () i

for (int $i=0 ; i<6400 ; i++$ ) //Forward 5000 steps

i

digitalWrite (DIR, IOW) digitalWrite (ENA, HIGH) ; digitalWrite (PUL, HIGH); delaymicroseconds (40); digitalwrite (PUL, IOW) delaymicroseconds (50); digitalWrite (DIR1, LOW) ; digitalWrite (ENA1, HIGH) digitalWrite (PUL1, HIGH) ; delayMicroseconds (50): digitalWrite (PUL1, IOW); delayMicroseconds (50); digitalwrite (DIR2, LOW) ; digitalWrite (ENA2, HIGH); digitalWrite (PUL2, HIGH) delayMicroseconds $(50)$; digitalWrite (PUL2, LOW)

delayMicroseconds $(50)$;

Figure25: Arduino code

\section{CONCLUSIONS}

In this paper a $3 \mathrm{D}$ model was built in Solidworks for the CNC machine, then stimulating the working area. Based on FEA performed in Solidworks on the mobile machine to evaluate its ability to withstand payload and to check the deformation and the safety factor for Steel and Aluminum. Steel material passed the test successfully, therefore, Steel was selected because of its higher yield strength and factor of safety, and its fewer deformation and strain.

The inverse kinematic of the derived parallel platform position has been sequentially analyzed, and the relationship between input tool position (X-Y-Z) and actuated control position is briefly expressed.

Solidworks model has been transferred to Simulink environment for dynamics simulation, relations between motor rev/min and movable platform position was inferred. Also, motors input torque and movable platform position relation was concluded. A PID controller was used to control the movable platform position against motors input torques.

The built prototype was intentionally made out of commercially available low-cost material to arrive at the final design quickly. No further effort was put into a precise evaluation of the prototype. A coarse evaluation of the workspace, orientability, speed, load-carrying capacity and system control is given for future better actual machine design guidance.

The achieved design is supposed to serve as a rapid prototyping example of a successful low cost and fully operational Stewart platform portable CNC machine. At the current stage the prototype is certainly not precise enough for manufacturing purpose.

A control based MATLAB-Simulink Package will be designed for the developed system, using PID and Artificial intelligence techniques for future work to control 
precisely the movable platform position, speed, and output torque.

\section{Credit Authorship Contribution Statement}

Mohamed A.O. Elamirali: conceptualization, formal analysis, investigation, resources, original draft; Elmoushi Elsayed: methodology, supervision; Sabreen A Abdelwahab: methodology, validation, supervision, formal analysis, review and editing.

\section{Declaration of Competing Interest}

The authors declare that they have no known competing financial interests or personal relationships that could have appeared to influence the work reported in this paper.

\section{References}

[1] L. Uriarte, M. Zatarain, D. Axinte, J. Yagüe-Fabra, S. Ihlenfeldt, J. Eguia, \& A. Olarra, "Machine tools for large parts," CIRP Ann. - Manuf. Technol., vol. 62, no. 2, pp. 731-750, 2013, doi: 10.1016/j.cirp.2013.05.009.

[2] D. Stoddart, and R. Holden, "Innovative Metrology Integrated Robot Cell for Machining Stainless Steel in the Manufacture of Nuclear Reaction Chambers", SAE AeroTech Congress, Toulouse, 2011.

[3] J. Tlusty, J. Ziegert, and S. Ridgeway, "Fundamental comparison of the use of serial and parallel kinematics for machine tools", Annals of the CIRP, vol. 48, no.1, pp. 351-356, 1999 https://www.sciencedirect.com/science/article/abs/pii /S0007850607632004.

[4] M. Weck and D. Staimer, "Parallel kinematic machine tools - Current state and future potentials," CIRP Ann. - Manuf. Technol., vol. 51, no. 2, pp. 671-683, Jan. 2002, doi: 10.1016/S0007-8506(07)61706-5

[5] "maxresdefault.jpg

$(1280 \times 720) . "$ https://i.ytimg.com/vi/QrAdITL9PpI/maxresdefault.j pg (accessed Jan. 5, 2020).

[6] C. Llopis-Albert, F. Rubio, S. Zeng, and H. Liao, "Applied mathematics for engineering problems in biomechanics and robotics," Math. Probl. Eng., vol. 2019, 2019, doi: 10.1155/2019/2578916.

[7] N. Hennes, "Machine tools for future oriented production," Laser Metrol. Mach. Perform. VI, vol. 44, no. Lcc, pp. 287-314, 2003.

[8] N. Hennes, "Ecospeed, an innovative machinery concept for high performance 5-axis machining of large structural components in aircraft engineering", Proc.of the 3rd Chemnitz Parallel Kinematic Seminar, Chemnitz, Germany, pp.763-774, 2002.

[9] Q. Li, X. Chai, and Q. Chen, "Review on 2R1T 3-DOF parallel mechanisms," Kexue Tongbao/Chinese Science Bulletin. Vol. 72, no. 14, pp.15071519, 2017, doi: 10.1360/N972015-01228.

[10] C. Hu, B. Yao, Q. Wang, Z. Chen, and C. Li, "Experimental investigation on high-performance coordinated motion control of high-speed biaxial systems for contouring tasks," Int. J. Mach. Tools
Manuf., vol. 51, no. 9, pp. 677-686, 2011, doi: 10.1016/j.ijmachtools.2011.06.001.

[11] J. Zhang, Y. Q. Zhao, and H. W. Luo, "Hybridmodel-based stiffness analysis of a three-revoluteprismatic-spherical parallel kinematic machine," Proc. Inst. Mech. Eng. Part B J. Eng. Manuf., vol. 231, no. 14, pp. 2561-2576, 2017, doi: $10.1177 / 0954405416634257$.

[12] R. Neugebauer, M. Wabner, H. Rentzsch, and S. Ihlenfeldt, "Structure principles of energy efficient machine tools," CIRP J. Manuf. Sci. Technol., vol. 4, no. 2, pp. 136-147, Jan. 2011, doi: 10.1016/j.cirpj.2011.06.017

[13] M. Schwaar, T. Schwaar, S. Ihlenfeldt, and H. Rentzsch " Mobile 5-axes machining centres. In sustainable production for resource efficiency and ecomobility", Proceedings of the 1st International Chemnitz Manufacturing Colloquium (ICMC 2010). Verlag Wissenschaftliche Scripten, Chemnitz (pp. 169-184).

[14] J. Zulaika, and F.J. Campa, " New concepts for structural components, In: López de Lacalle L., Lamikiz A. (eds), Machine Tools for High Performance Machining", London, Springer Verlag, pp. 47- 73, 2010, https://doi.org/10.1007/978-184800-380-4_2.

[15] D. A. Axinte, S. Abdul Shukor, and A. T. Bozdana, "An analysis of the functional capability of an inhouse developed miniature 4-axis machine tool," Int. J. Mach. Tools Manuf., Vol. 50, no. 2, pp. 191-203, 2010, doi: 10.1016/j.ijmachtools.2009.10.005.

[16] H. N. Hansen, T. G. Eriksson, M. Arentoft, and N. A. Paldan "Design rules for microfactory solutions," 5th Int. Work. Microfactories, Becanson, France, 25-27 October, 2006. http://www.lab.cnrs.fr/iwmf06/

[17] J. L. Liow, "Mechanical micromachining: a sustainable micro-device manufacturing approach?," J. Clean. Prod., vol. 17, no. 7, pp. 662-667, May 2009, doi: 10.1016/j.jclepro.2008.11.012.

[18] S. Mussa, and G. Zettl, 2011, "Steigerung der Energieeffizienz in der Produktion: Energieeffiziente Produktionsmaschinen. 4. Fachtagung Energieeffiziente Fabrik in der Automobilproduktion, 8-9 Feb., Munich, Germany.

[19] R. Neugebauer, A. Bucht, A. Illgen, and V. Wittstock, "Piezobasierte aktor-sensorEinheit zur Uniaxialen Schwingungskompensation," ZWF Zeitschrift fuer Wirtschaftlichen Fabrikbetr., vol. 102, no. 7-8, pp. 451-455, May 2007, doi: 10.3139/104.101173.

[20] H. A. El Maraghy, "Flexible and reconfigurable manufacturing systems paradigms," Flex. Serv. Manuf. J., vol. 17, no. 4 SPECIAL ISSUE, pp. 261276, 2006, doi: 10.1007/s10696-006-9028-7.

[21] Y. Koren et al., "Reconfigurable manufacturing systems," CIRP Ann. - Manuf. Technol., 
Vol. 48, , no. 2, 1999, pp. 527-540, 1999, doi: 10.1016/S0007-8506(07)63232-6.

[22] M. Kannan and J. Saha, "A feature-based generic setup planning for configuration synthesis of reconfigurable machine tools," Int. J. Adv. Manuf. Technol., vol. 43, no. 9-10, pp. 994-1009, 2009, doi: 10.1007/s00170-008-1779-8.

[23] T. Moriwaki, "Multi-functional machine tool," CIRP Ann. - Manuf. Technol., Vol. 57, no. 2, pp. 736-749, 2008, doi: 10.1016/j.cirp.2008.09.004.

[24] W. Liping, X. Huayang, G. Liwen, and Z. Yu, "A novel 3-PUU parallel mechanism and its kinematic issues,” Robot. Comput. Integr. Manuf., Vol. 42, pp. 86-102 2016, doi: 10.1016/j.rcim.2016.05.003.

[25] L. Wang, H. Xu, and L. Guan, "Optimal design of a 3-PUU parallel mechanism with 2R1T DOFs," Mech. Mach. Theory, Vol. 114, pp. 190-203, 2017, doi: 10.1016/j.mechmachtheory.2017.03.008.

[26] W. Liping, X. Huayang, and G. Liwen, "Kinematics and inverse dynamics analysis for a novel 3-PUU parallel mechanism," Robotica, vol. 35, no. 10, pp. 2018-2035, 2017, doi: 10.1017/S0263574716000692.

[27] Y. Li and Q. Xu, "Stiffness analysis for a 3-PUU parallel kinematic machine," Mech. Mach. Theory, vol. 43, no. 2, pp. 186-200, 2008, doi: 10.1016/j.mechmachtheory.2007.02.002.

[28] "Designers SOLIDWORKS", https://www.solidworks.com/solution/jobfunctions/designers (accessed Jan. 21, 2020)
[29] R. Sam, K. Arrifin, and N. Buniyamin, "Simulation of pick and place robotics system using solidworks softmotion,” Proc. 2012 Int. Conf. Syst. Eng. Technol. ICSET 2012, 11-12 Sept. 2012, Bandung, Indonesia, doi: 10.1109/ICSEngT.2012.6339325.

[30] T. M. Altalmas, S. Ahmad, A. Aula, R. Akmeliawati, and S. N. Sidek, "Mechanical design and simulation of two-wheeled wheelchair using solidworks," IOP Conf. Ser. Mater. Sci. Eng., vol. 53, no. 1, 5th International Conference on Mechatronics (ICOM'13) 2-4 July 2013, Kuala Lumpur, Malaysia 2013, doi: 10.1088/1757-899X/53/1/012042.

[31] "AISI 1035 Carbon Steel (UNS G10350)." https://www.azom.com/article.aspx?ArticleID=6540 (accessed Feb. 11, 2020).

[32] "Wrought aluminum alloy 1060 [SubsTech]." https://www.substech.com/dokuwiki/doku.php?id=w rought_aluminum_alloy_1060 (accessed Feb. 11, 2020).

[33] "Simulink model design", https://www.mathworks.com/search.html?c\%5B\%5D $=$ entire_site $\& \mathrm{q}=$ Simulink model design $\&$ page $=1$ (accessed Feb. 23, 2020). 